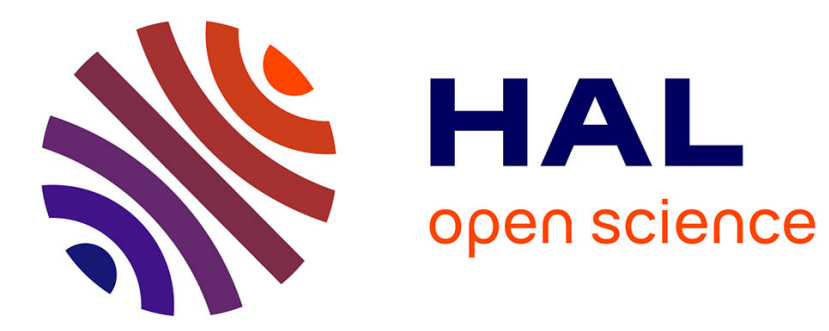

\title{
Complement activation links inflammation to dental tissue regeneration
}

Madison Bergmann, Charlotte Jeanneau, Thomas Giraud, Gilles Richard, Imad About

\section{- To cite this version:}

Madison Bergmann, Charlotte Jeanneau, Thomas Giraud, Gilles Richard, Imad About. Complement activation links inflammation to dental tissue regeneration. Clinical Oral Investigations, 2020, 24 (12), pp.4185-4196. 10.1007/s00784-020-03621-w . hal-03191393

\section{HAL Id: hal-03191393 https://hal.science/hal-03191393}

Submitted on 7 Apr 2021

HAL is a multi-disciplinary open access archive for the deposit and dissemination of scientific research documents, whether they are published or not. The documents may come from teaching and research institutions in France or abroad, or from public or private research centers.
L'archive ouverte pluridisciplinaire HAL, est destinée au dépôt et à la diffusion de documents scientifiques de niveau recherche, publiés ou non, émanant des établissements d'enseignement et de recherche français ou étrangers, des laboratoires publics ou privés. 


\section{Complement activation links inflammation to dental tissue regeneration}

Madison Bergmann ${ }^{1}$, Charlotte Jeanneau ${ }^{1}$, Thomas Giraud ${ }^{1,2}$, Gilles Richard ${ }^{3}$, Imad About ${ }^{1 *}$

${ }^{1}$ Aix Marseille Univ, CNRS, ISM, Inst Movement Sci, Marseille, France.

${ }^{2}$ APHM, Hôpital Timone, Service d'Odontologie, Marseille, France.

${ }^{3}$ Septodont, Saint-Maur-des-fossés, France.

* Corresponding author :

Prof. Imad About

Université d'Aix-Marseille, Faculté d'Odontologie

Institut des Sciences du Mouvement (ISM), UMR 7287 CNRS \&

27 BD Jean Moulin

13385 MARSEILLE cedex 5

France

Tel: 0486136859

email: imad.about@univ-amu.fr

Running title: Complement links inflammation to regeneration 


\begin{abstract}
:
Objectives: Complement is an efficient plasma immune surveillance system. It initiates inflammation by inducing vascular modifications and attracting immune cells expressing Complement receptors. Investigating Complement receptors in non-immune cells pointed out Complement implication in the regeneration of tissue such as liver, skin or bone. This review will shed the light on its Complement implication in the initial steps of dental tissue regeneration.
\end{abstract}

Materials and methods: Review of literature was conducted on Complement local expression and implication in oral tissue regeneration in vivo and in vitro.

Results: Recent data reported expression of Complement receptors and soluble proteins in dental tissues. Cultured pulp fibroblasts secrete all Complement components. Complement C3b and MAC have been shown to control bacteria growth in the dental pulp while C3a and C5a are involved in the initial steps of pulp regeneration. Indeed, C3a induces pulp stem cell/fibroblast proliferation, and fibroblast recruitment, while C5a induces neurite growth, guides stem cell recruitment and odontoblastic differentiation. Similarly, cultured periodontal ligament cells produce $\mathrm{C} 5 \mathrm{a}$ which induces bone marrow mesenchymal stem cell recruitment.

Conclusions: Overall, this review highlights that local Complement synthesis in dental tissues plays a major role, not only in eliminating bacteria, but also in the initial steps of dental tissue regeneration, thus, providing a link between dental tissue inflammation and regeneration.

Clinical relevance: Complement provides an explanation for understanding why inflammation preceeds regeneration. This may also provide a biological rational for understanding the reported success conservative management of mature permanent teeth with carious pulp exposure.

\title{
Keywords
}

Pulp biology, stem cell recruitment, dental tissue regeneration, Complement, pulp inflammation, nerve sprouting. 


\section{Introduction}

Tissue regeneration is a physiological process which occurs only after physical/traumatic injuries or under pathological conditions with tissue lesions, due to endogenous or exogenous stimuli. This leads to acute inflammation inducing secretion of pro-inflammatory mediators (e.g., interferon $\gamma$ [INF $\gamma]$, tumor necrosis factor $\alpha$ [TNF- $\alpha$ ], interleukin $1 \beta$ [IL1 $\beta]$, IL8 ), and the recruitment of phagocytic cells [1]. The inflammatory reaction represents a protective response of tissues by eliminating noxious stimuli and initiating the healing/regeneration process [2]. It is characterized by capillary dilatation and leukocyte recruitment to the inflammatory site leading to the appearance of four clinical symptoms: pain, redness, heat, and function loss. This is followed by the inflammation resolution which is regulated by multiple mediators and immune cells [3]. This phase takes place a few hours after the initiation of the acute inflammatory response. Inflammatory stimuli are eliminated and secretion of proinflammatory mediators such as TNF- $\alpha$ and IL-8 decreases while that of anti-inflammatory mediators such as IL4, IL10, and IL13, and Chemokine Ligand 2 (CCL2), increases. The resolution of inflammation is a prerequisite to initiate tissue healing/regeneration by the recruitment of stem cells. Indeed, failure to resolve acute inflammation may lead to chronic inflammation due to continuous stimulation. In this case, the recruited mononuclear cell infiltrate persists at the injury site $[4,5]$. Infiltrated cells produce pro-inflammatory cytokines such as IFN $\gamma$ and TNF- $\alpha$ which polarize macrophages to a pro-inflammatory M1 phenotype rather than an anti-inflammatory tissue-repair M2 phenotype.

Infiltrating immune cells during the inflammation appear to play a major role in determining the outcome of wound repair. In salamander limb regeneration model, it has been shown that macrophage depletion resulted in failure of limb regeneration [6].

Complement is one of the main actors of the innate immunity. It is known for its roles in initiating the acute inflammatory reaction through production of $\mathrm{C} 3 \mathrm{a}$ and $\mathrm{C} 5 \mathrm{a}$ anaphylatoxins which induce blood vessel dilatation and recruitment of phagocytic cells to the inflammatory site. Complement is also involved in the resolution phase by producing $\mathrm{C} 3 \mathrm{~b}$ opsonin which facilitate bacteria phagocytosis and by forming the membrane attack complex (MAC) which leads to direct pathogen lysis (Fig. 1). Thus, Complement plays a beneficial role in acute inflammation and its resolution. However, Complement activation may have deleterious effects by contributing to inflammation-mediated tissue damage. Also, inherited/acquired complement deficiencies may lead to the development of autoimmunity [7].

Complement receptors are known to be expressed by immune cells. Yet, an expression of complement receptors has been reported in many other cell types suggesting Complement implication in other physiological processes and expression of Complement receptors in mesenchymal stem cells 
lead to the hypothesis that Complement is involved in tissue regeneration [8]. In vivo studies confirmed Complement implication in the regeneration process of several tissues such as liver, bone or skin [9]. In periodontal tissues, Complement implication in chronic inflammation is well established. However, little is known about its role is dental tissue regeneration. This review will shed the light on dental cells as an important local source of Complement proteins and highlight Complement implication in the initial steps of dental tissue regeneration.

\section{The complement system}

Heat labile proteins circulating in the serum were identified early in the $19^{\text {th }}$ century. These proteins were later named the complement system as they were hypothesized to complement the activity of the innate immune system [10]. Complement proteins are primarily secreted by liver hepatocytes [11] and some immune cells [12]. So far, more than 30 soluble and membrane-bound proteins have been identified as a part of this cascade which can be activated by 3 different pathways [13]: the classical, the lectin and the alternative pathways (Fig. 1). In the classical pathway, Complement activation is initiated by fixation of antibodies to pathogen surface antigens $[14,15]$. In the lectin pathway, Complement is activated after fixation of mannose-associated serine protease (MASP) to either mannose-binding lectin (MBL) or ficolin. MBL and ficolin belong to the lectin proteins family, recognizing pathogen-associated molecular patterns (PAMPs) [16]. The alternative pathway is activated directly by pathogens or biomaterials. Upon tooth lesion/injury, these three pathways can be activated by dental caries/traumas and after application of pulp capping/bone filling materials [17]. Complement activation by all three pathways ends up with a common pathway leading to production of a protein complex with an enzymatic activity, C3 convertase. The latter's enzymatic activity leads to production of several active molecules responsible for Complement functions: $\mathrm{C} 3 \mathrm{a}$ and $\mathrm{C} 5 \mathrm{a}$ act as anaphylatoxins with pro-inflammatory activity; C3b acts as an opsonin; and membrane attack complex C5b-9 (MAC) which acts as a lytic membrane complex (Fig. 1). C3a and C5a action is dependent on binding to their specific G coupled receptors. While $\mathrm{C} 3 \mathrm{aR}$ is the only known receptor for $\mathrm{C} 3 \mathrm{a}$, there are 2 identified receptors for $\mathrm{C} 5 \mathrm{a}$ namely C5aR and C5L2 [18]. Immune cells express either C3a or C5a receptor or both [19]. Due to similarities in their structure and in the structure of their receptors, both anaphylatoxins have overlapping functions. Thus, C3a and C5a promote release of pro-inflammatory mediators such as IL-6, IL-1 $\beta$ and TNF- $\alpha[20,21]$, induce and leukocyte recruitment to the inflammation site and modulate their phagocytic activity. However, there are some functions that are specific either to C3a or C5a. For example, $\mathrm{C} 3 \mathrm{a}$ is responsible for attracting eosinophils, masts cells and dendritic cells during the inflammatory process, while C5a regulates B cells migration and modulates T cells activity [22].

The other fragments resulting from C3 and C5 cleavage, respectively C3b and C5b, exert other functions in the inflammation. $\mathrm{C} 3 \mathrm{~b}$ is an opsonin playing a major role in eliminating pathogens by binding to pathogen surface and being recognized by immune cells' specific receptors [23] whereas C5b 
is responsible of MAC assembly (C5b, C6, C7, C8 and C9) (Fig. 1). This protein complex is directly involved in the destruction of pathogens as it is mainly responsible for the lysis of parasites, Gram negative, and Gram positive bacteria [24].

Thus, Complement is an important actor of the innate immune system. It induces vascular modifications during in the acute inflammation and plays a significant role in its resolution by eliminating pathogens. However, expression of complement receptors and components in non-immune cells raised questions about possible functions in other processes than the inflammation, namely in tissue regeneration.

\section{Complement functions in tissue regeneration}

Complement is expressed in most organisms and it is conserved throughout evolution. Although local Complement secretion could potentiate the immune response, its secretion during regeneration in urodeles suggested that it may be involved in other functions. Indeed, after amputation, urodeles have the capacity to regrow limbs and it has been shown that $\mathrm{C} 3$ is expressed during urodele limb regeneration. Using both western blot and immunofluorescence, C3 was detected at early stages of dedifferentiation as well as in regenerating muscles and cartilage [25]. This was the first study to highlight Complement implication, namely C3, in limb regeneration. Expression of C3 and C5 was also studied after limb amputation in newts. While $\mathrm{C} 3$ was expressed throughout the entire limb regeneration process, C5 was mainly expressed in the wound epithelium, an early stage of regeneration. This means that Complement plays a significant role during limb regeneration and that there is a differential expression pattern of Complement proteins during the regeneration process [26]. Complement has also been shown to be involved in mammalian tissue regeneration (Fig. 2). Complement C5 has been shown to be required for efficient liver regeneration after toxic injury using carbon tetrachloride $\left(\mathrm{CCl}_{4}\right)$ in a murine model. While liver fully regenerated after toxic injury in normal mice, regeneration was not found in C5-deficient mice which showed evidence of tissue degeneration and necrosis. Lack of C5 led to deficient hepatocyte proliferation due to a diminished hepatocyte mitotic activity indicating that $\mathrm{C} 5$ is a potential mitotic factor for hepatocytes. Interestingly, liver regeneration capacity in C5-deficient mice was restored after injecting C5 protein or C5a fragment. This leads to the conclusion that C5a, is required for efficient liver regeneration after toxic injury [27].

Similarly, several Complement proteins/receptors have been detected during bone regeneration and appear to play a major role in this process [28]. Complement $\mathrm{C} 1 \mathrm{~s}$ was detected during cartilage resorption [29] and contributes to its collagen matrix degradation [30]. This is particularly important for cartilaginous template resorption before ossification of newly regenerated bone. Complement $\mathrm{C} 3$ and $\mathrm{C} 5$ as well as their respective $\mathrm{C} 3 \mathrm{aR}$ and $\mathrm{C} 5 \mathrm{aR}$ receptors were detected using RT-PCR and immunofluorescence in mesenchymal stem cells as well as in osteoblasts and osteoclasts [31]. Both molecules have been shown to induce osteoclast differentiation. A difference in C3aR expression pattern 
was observed in vitro after stimulation of osteoblast with $\mathrm{C} 3 \mathrm{a}$ : while $\mathrm{C} 3 \mathrm{aR}$ was detected at the cell surface in the absence of $\mathrm{C} 3 \mathrm{a}$, the receptor was translocated into the cytoplasm or bound to the nuclear membrane after adding C3a. Further analysis showed an increase in C5 mRNA levels during osteogenic differentiation in vitro, indicating that $\mathrm{C} 5 \mathrm{aR}$ expression was strong in cells undergoing osteogenic differentiation whereas it was poorly expressed in undifferentiated mesenchymal stem cells. These results obtained in vitro, underline the importance of C5a and C3a for bone tissue regeneration [31]. In order to determine $\mathrm{C} 5 \mathrm{aR}$ expression pattern during bone regeneration in vivo, immunostaining was performed at different time points after rat tibia fracture [32]. C5aR was expressed after 1 day by the immune cells at the inflammation site. Once the inflammation was resolved, C5aR was expressed by osteoblasts from 3 up to 28 days in the newly formed bone. Chondroblastic cells in the cartilage template also expressed C5aR from day 7 to 28 . However, C5aR expression in the chondroblastic cells was less intense in the hypertrophic region where the cartilaginous template is replaced by bone [32].

Complement was also investigated during skin healing which is a multistep process finely regulated by many growth factor and cells. Complement has been shown to play a role in the early phase of inflammation mainly through $\mathrm{C} 3$ and $\mathrm{C} 5$ involvement in vasodilatation and recruitment of inflammatory cells [33]. Complement deficiency has been shown to promote cutaneous wound healing in mice [34]. By contrast, recent studies performed in vivo showed that a local application of either C5a, or C3a or both [35-37] induced wound healing through fibroblast migration and collagen deposition at day 3 to 7 .

Thus, in addition to its implication in initiating the inflammatory reaction and its resolution Complement is also involved in the regeneration process of several tissues.

\section{Complement implication in the initial steps of dental tissue regeneration}

Dental tissues are frequently exposed to infection and injury. However, they exhibit a high resistance to infection and regenerate following infectious/traumatic injuries or application of bone filling/pulp capping materials. This suggests that these tissues may contribute to infection control and have a significant regeneration potential.

\section{a) Complement production in the periodontal ligament: implication in bone marrow mesenchymal stem cell recruitment}

A close relationship exists between maxillary/mandibular bones and the surrounding periodontal ligament which is prone to a high infection/injury risk. In chronic inflammation, local Complement activation has been shown to induce periodontal inflammatory activity and periodontal bone support destruction $[38,39]$. Complement components were abundantly found in the gingival crevicular fluid (GCF) of periodontitis patients, whereas they were present at lower concentrations in GCF from healthy 
individuals [40]. Studies in mice have implicated both $\mathrm{C} 3$ and $\mathrm{C} 5 \mathrm{aR}$ in periodontal disease pathogenesis. In a proof-of-concept study, local intragingival injection of PMX-53, a C5aR antagonist, blocked periodontal inflammation and bone loss in a model of $P$. gingivalis-induced periodontitis [39]. This demonstrates a deleterious effect of Complement in chronic disease.

By contrast, a recent study performed in vitro has demonstrated that Complement plays a significant role in bone marrow mesenchymal stem cell recruitment which is required for periodontal bone regeneration [41]. Cultures of periodontal ligament cells, isolated from human third molars and physically injured by scalpels, demonstrated that PDL express C5 and produce C5a. PDL cell physical injury simulates tissue injury upon extraction/trauma. C5a production level doubled when PDL cells were incubated with extracts from bone filling materials such as Gen-Os® of equine and porcine origins. When C5a produced by PDL cells was incubated with human bone marrow mesenchymal stem cells (BMMSCs), C5a bound to BMMSC C5aR and induced its subsequent phosphorylation. Additionally, both C5a binding and C5aR phosphorylation further increased with PDL supernatants incubated with the abovementioned bone filling materials. Binding of C5a to BMMSC C5aR induced their proliferation and recruitment towards injured PDL cells. Both BMMSC proliferation and recruitment significantly increased when the PDLs were incubated with Gen-Os ${ }^{\circledR}$ bone filling materials [41].

Thus, PDL cells produce C5a leading to BMMSC proliferation and C5a-dependent recruitment and these effects can be modulated by bone filling materials. This demonstrates Complement implication in two important steps for bone regeneration: bone marrow mesenchymal stem cell proliferation and recruitment the stimulation/injury site.

b) Complement production in the pulp: implication in the initial steps of dental pulp regeneration

\section{Complement contribution to the resolution of pulp infection/inflammation}

Upon carious decays, one of the major risks is the subsequent inflammation as a severe inflammatory reaction may lead to pulp tissue necrosis. This is due to the fact that the dental pulp is located within inextensible dentinal walls and has a terminal vascularization [42]. This high risk of necrosis represents a challenge and explains why the resolution of the inflammation is a pre-requisite for dentin-pulp regeneration. Thus, local inflammation control is a major requirement for tissue regeneration. Recent data demonstrated that local Complement production is involved in the resolution of pulp inflammation. In vitro models using primary pulp fibroblast cultures have been used to simulate bacterial invasion of the pulp using lipoteichoic acid (LTA) from Gram positive or lipopolysaccharides (LPS) from Gram negative bacteria. Surprisingly, pulp fibroblasts express most Complement mRNAs. Yet, after LTA stimulation, not only they expressed all Complement mRNAs, but they also secreted Complement active proteins such as $\mathrm{C} 3 \mathrm{a}, \mathrm{C} 3 \mathrm{~b}, \mathrm{C} 5 \mathrm{a}, \mathrm{C} 5 \mathrm{~b}$ and even more complex structures such as the 
Membrane Attack Complex (C5b-9) [43]. Among these active molecules, C3b and MAC play two major roles in the resolution of inflammation: when $\mathrm{C} 3 \mathrm{~b}$ was incubated in vitro with cariogenic bacteria such as S. Mutans and S. Sanguinis, it opsonized these bacteria and enhanced their phagocytosis by macrophages [44]. When pulp fibroblasts were co-cultured with cariogenic bacteria, immunofluorescence and ELISA demonstrated MAC secretion and fixation on S. Mutans and S. Sanguinis leading to their subsequent lysis as demonstrated by a significant reduction of bacteria growth [45]. Investigating Complement expression in carious human teeth demonstrated an intense expression of MAC on bacteria penetrating the dentin tubules and the dental pulp. Within the limit of these studies in vitro, pulp fibroblast-produced Complement is involved in the control of bacteria which may enter the pulp under caries (Fig.3). This pathogen control represents a pre-requisite for the regeneration process. Thus, in addition to systemic Complement anti-bacteria functions, local Complement production within the dental pulp potentiates these effects, contributes to the resolution of inflammation, and represents an efficient first line of defense against pulp invading bacteria.

\section{Complement implication in dentin-pulp regeneration}

The first evidence of Complement implication in dentin-pulp regeneration came from expression of Complement receptors in dental pulp stem cells (DPSCs) and fibroblasts. Indeed, investigating $\mathrm{C} 3 \mathrm{aR}$ by immunohistochemistry demonstrated its co-expression with STRO-1 mesenchymal stem cell marker in dental pulp stem cells or with fibroblast surface protein antigen in pulp fibroblasts in vitro [46] and on healthy tooth sections. Similarly, Complement C5aR and STRO-1 co-localization on sound human tooth sections highlighted a possible implication of Complement C5aR in the dentin-pulp regeneration process [47]. This was further confirmed in vitro by demonstrating C5aR expression in dental pulp stem cells by RT-PCR and co-localization of C5aR and STRO-1 by immunofluorescence in DPSCs [47].

Complement $\mathrm{C} 3 \mathrm{a}$ is the first active molecule produced after Complement activation. Investigating C3a interaction with pulp cells demonstrated a significant increase of DPSCs and pulp fibroblasts proliferation in a concentration-dependent manner [46]. Implication of C3a in cell recruitment was studied following cell migration using microfluidic chambers. These chambers allow establishing a chemotaxis gradient and enable tracking single cell migration following a chemotaxis factor overtime. When pulp fibroblasts were incubated with $\mathrm{C} 3 \mathrm{a}$ in microfluidic chambers, they migrated following a C3a gradient [46]. When the effect of this molecule was investigated on DPSCs, C3a induced their mobilization only. Although their migration did not follow any specific direction, cell detachment and mobilization from its surrounding environment and underlying substrate is an initial requirement for its recruitment. Application of C3 specific antagonist (SB290157) significantly inhibited stem cell mobilization and fibroblast recruitment. This clearly demonstrates that, in addition 
to fibroblast and dental pulp stem cell proliferation, C3a mobilizes stem cells and provides a gradient for pulp fibroblast recruitment (Fig. 4).

To investigate the role played by C5a in the initial steps of regeneration, models of tissue infection and injury were developed to simulate carious or traumatic pulp injuries in vitro. When cultured fibroblasts were injured or stimulated with LTA, they increased C5a secretion very rapidly as a significant increase was observed after 20 or 30 minutes of stimulation. When C5a was applied as a chemotactic factor using microfluidic chambers, it enhanced pulp stem cell recruitment and this migration followed a C5a gradient [47]. This indicates that Complement activation at the injury site provides $\mathrm{C} 5 \mathrm{a}$ as a major signal for guiding stem cell recruitment. Thus, while $\mathrm{C} 3 \mathrm{a}$, mobilizes stem cells, C5a guides their migration to the injury/decay/biomaterial application site. This secretion level and its subsequent effect on mesenchymal stem cell recruitment has been shown to be modulated by pulp capping materials. Indeed, a decreased DPSC recruitment was reported with resin-containing pulp capping materials [48].

Further adaptation of microfluidic chambers to simulate carious injury and interaction of LTAstimulated fibroblasts with either DPSCs or human neurons unraveled the interactions between fibroblast injury under caries and DPSCs recruitment/neurite sprouting. Indeed, when DPSCs were subjected to LTA-stimulated/unstimulated fibroblasts in these chambers, DPSCs migrated towards LTA-stimulated cells. Addition of C5a specific antagonist (W54011) significantly reduced this recruitment [43]. This indicates that C5a released from injured fibroblasts upon carious/traumatic injuries guides stem cell towards the injury site (Fig. 5). Interestingly, investigating C5aR expression on sound human tooth sections or cultured cells demonstrated that pulp fibroblasts do not express C5aR. However, a strong expression of this receptor was found under caries, in LTA-stimulated fibroblasts [49] and in LPS-stimulated pulp cells [50]. Thus, upon carious injury, an increased production of C5a at the carious site is expected to interact with the fibroblast C5a receptor. Indeed, when C5a was incubated with LTA-stimulated fibroblasts, the latter secreted Brain-Derived Neurotrophic Factor (BDNF), a major neurite outgrowth inducer. Secretion of BDNF resulted from binding of C5a to its specific C5aR and its subsequent phosphorylation [49]. This model demonstrated that LTA-stimulated pulp fibroblasts control neurite outgrowth through BDNF modulation via C5a secretion as demonstrated by the neurites sprouting towards LTA-stimulated fibroblasts (Fig. 5). Thus, in addition to C5a implication in dental pulp stem cell recruitment, local Complement activation under carious injury is involved in neurite sprouting and nerve regeneration which are major requirements in the dental pulp regeneration.

While the abovementioned C5a effects appear clearly related to C5a interaction with its C5aR, a second receptor for C5a, C5a receptor-like 2 (C5L2), was so far considered as a non-functional receptor. C5L2 belongs to the superfamily of $\mathrm{G}$ protein-coupled receptors $[51,52]$ but, unlike most $\mathrm{G}$ protein-coupled receptors, C5L2 is deficient in heterotrimeric G protein coupling. When C5L2 expression was investigated on human third molar tooth sections, immunohistochemistry showed a 
perivascular co-localization of both C5L2 and STRO-1 [53]. This was further confirmed on isolated human DPSCs where C5L2 expression and functions in the dental pulp provided valuable new insights to C5a receptors functions. Studying C5L2 expression by immunohistochemistry demonstrated a coexpression of this receptor with C5aR by LTA-stimulated fibroblasts [54]. Silencing C5L2 with small interfering RNA (siRNA) in pulp fibroblasts lead to an increased BDNF secretion [54]. Furthermore, neurite outgrowth significantly increased towards fibroblasts silenced for C5L2 [55]. This shows that C5L2 act as a modulator of BDNF secretion through inhibition of C5aR and demonstrates LTAstimulated fibroblasts implication in neurite sprouting during pulp regeneration.

Further investigation of Complement functions demonstrated that upon incubation in odontogenic medium, expression of C5L2 significantly increased in DPSCs undergoing odontoblastic differentiation. C5L2 expression appears to be potentiated by $\mathrm{TNF} \alpha$, a potent pro-inflammatory cytokine. C5L2-siRNA silencing strategy in DPSCs demonstrated that C5L2 acts as a negative regulator of expression of dentin matrix protein 1 (DMP1), a dentinogenic marker. This provides a direct correlation between odontoblastic differentiation and C5L2 expression level and identifies C5L2 as a negative regulator of DMP1 expression by DPSCs during odontoblastic differentiation. This provides a first evidence of C5L2 involvement in dental pulp stem cell functions and adds important data on the implication of Complement in dental pulp stem cells odontoblastic differentiation [53].

Overall, pulp fibroblast appears as a unique cell in its capacity to secrete all complement proteins. This secretion together with expression of complement receptors is modulated by caries/injury or application of biomaterials. Fibroblast-secreted C3a and C5a play a major role in the initial steps of dentin-pulp regeneration, as demonstrated in vitro, by interacting with their receptors on pulp fibroblasts, dental pulp stem cells and neurons inducing their proliferation/recruitment and odontoblastic differentiation.

\section{Conclusion}

Complement is an important immune surveillance system mainly synthesized by the liver. Through production of active molecules, Complement is known for its contribution in initiating acute inflammation and eliminating pathogens during its resolution. To render Complement more readily available, non-immune cells such as osteoblasts and chondrocyte have been shown to secrete some Complement proteins at the injury/inflammation site. Moreover, expression of Complement receptors has been reported in many non-immune cell types including stem cells demonstrating its implication in tissue regeneration.

Dental tissues are prone to infection/traumatic injuries and severe inflammation may lead to pulp necrosis/periodontal inflammation with subsequent bone resorption. This review highlights that, in addition to its implication in initiating the inflammation, Complement plays a major role in initiating the regeneration process within dental tissues. 
Recent investigations demonstrated that pulp fibroblast secrete/express Complement proteins/receptors highlighting local complement sources within the dental tissues. Through production of C3b and MAC [44, 45], pulp fibroblast-secreted Complement contributes to the resolution of inflammation by eliminating bacteria which is a prerequisite for the regeneration process. By producing C3a, C5a, pulp fibroblast-synthesized Complement contributes to tissue regeneration. While C3a mobilizes DPSCs and recruits pulp fibroblasts [46], C5a has a major role in the neurite outgrowth [49], DPSCs recruitment [47] and differentiation into odontoblast-like cells [53]. Similarly, PDL cellproduced C5a interacts with BMMSCs inducing their recruitment [41] which represents an important early step of periodontal ligament regeneration. Interestingly, Complement protein secretion/receptor expression modulation by injury/infection or after biomaterial application on periodontal/pulp cells highlights the dental tissue-synthesized Complement as an additional local immune surveillance mechanism and demonstrates its implication in inflammation and regeneration.

Throughout this review, it is now clear that, in addition to its implication in the initiation of inflammation, Complement plays a key role in both inflammation resolution and the initial steps of dental tissue regeneration, thus, providing at least one of the missing links between dental tissue inflammation and regeneration (Fig. 6). 
Legends

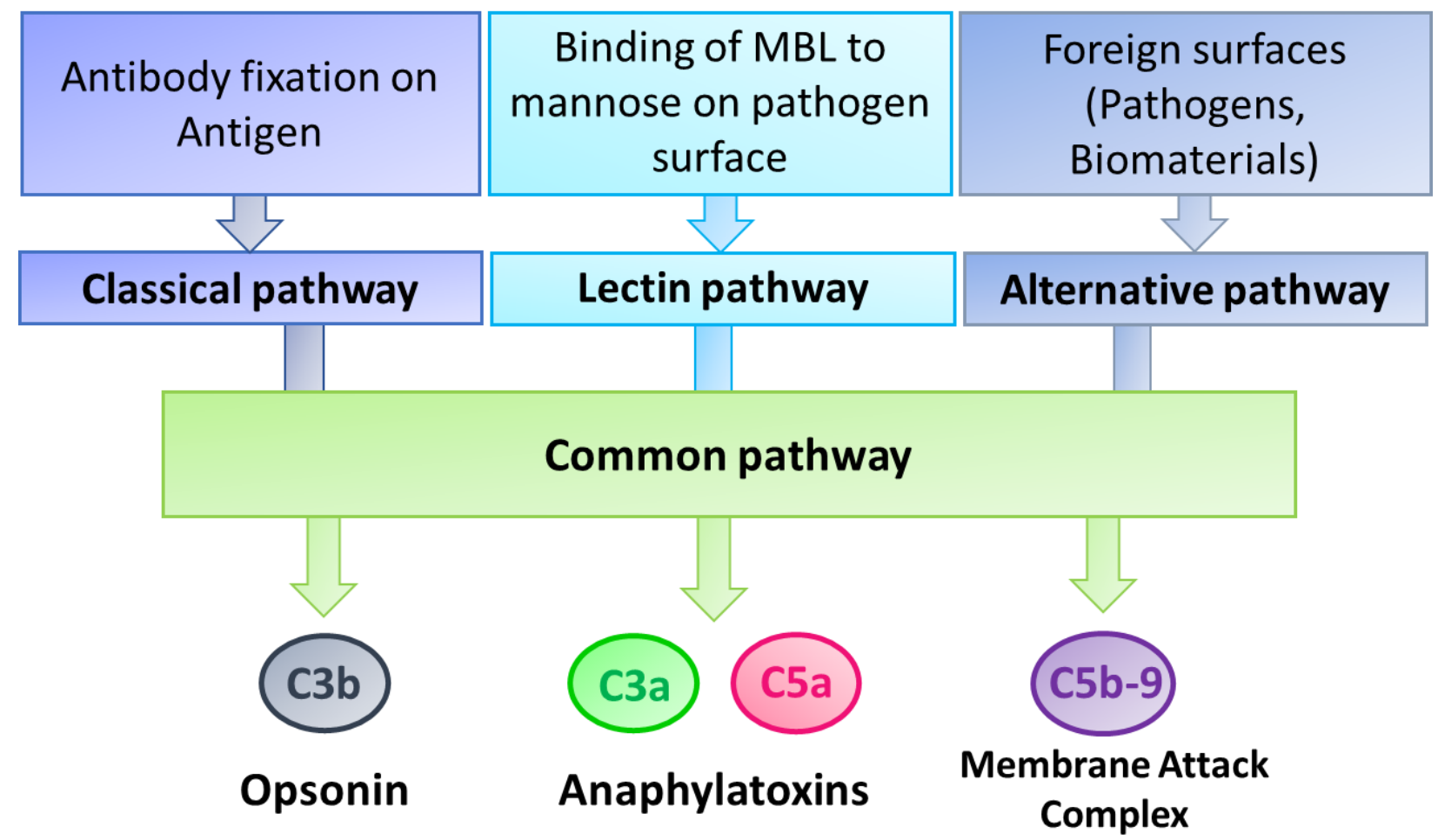

Figure 1: Complement activation pathways and bioactive molecules

Complement is activated by 3 pathways: classical, lectin and alternative pathways. All three activation pathways converge to a common pathway which leads to the production of the same bioactive molecules: $\mathrm{C} 3 \mathrm{~b}$ opsonin facilitating pathogen phagocytosis; $\mathrm{C} 3 \mathrm{a}$ and $\mathrm{C} 5 \mathrm{a}$ anaphylatoxins induce vessel vasodilatation during the inflammatory reaction, and membrane attack complex C5b-9 (MAC) which induces direct lysis of pathogens during the resolution phase of inflammation. 


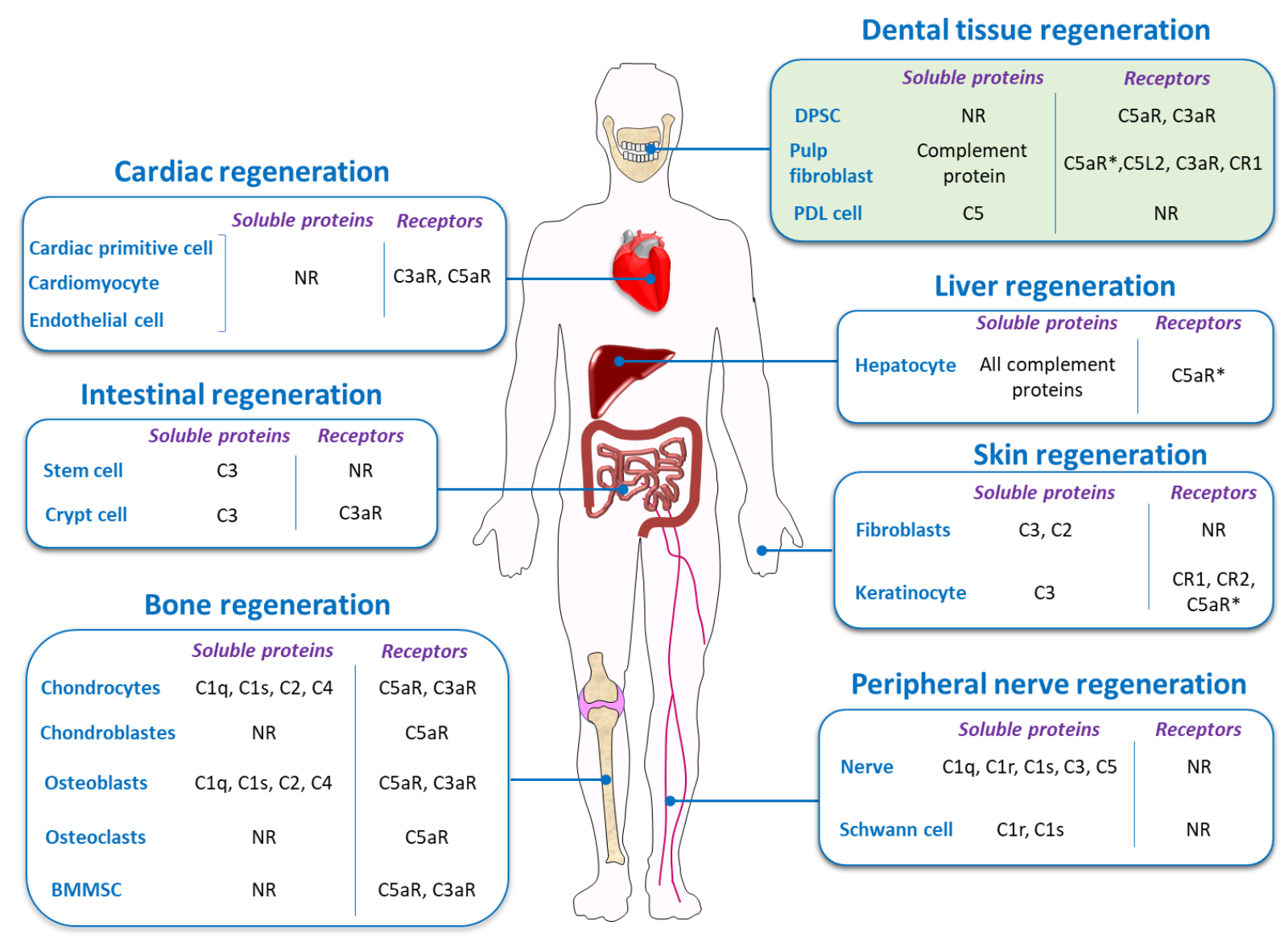

Figure 2: A sketch of Complement proteins/receptors in tissue regeneration.

Local Complement secretion is involved in Cardiac [56], intestinal [57], bone [8, 31, 58], nerve [59], skin $[60,61]$ and dental tissues regeneration $[46,49] . *=$ under stimulation; $N R=$ Non reported. 


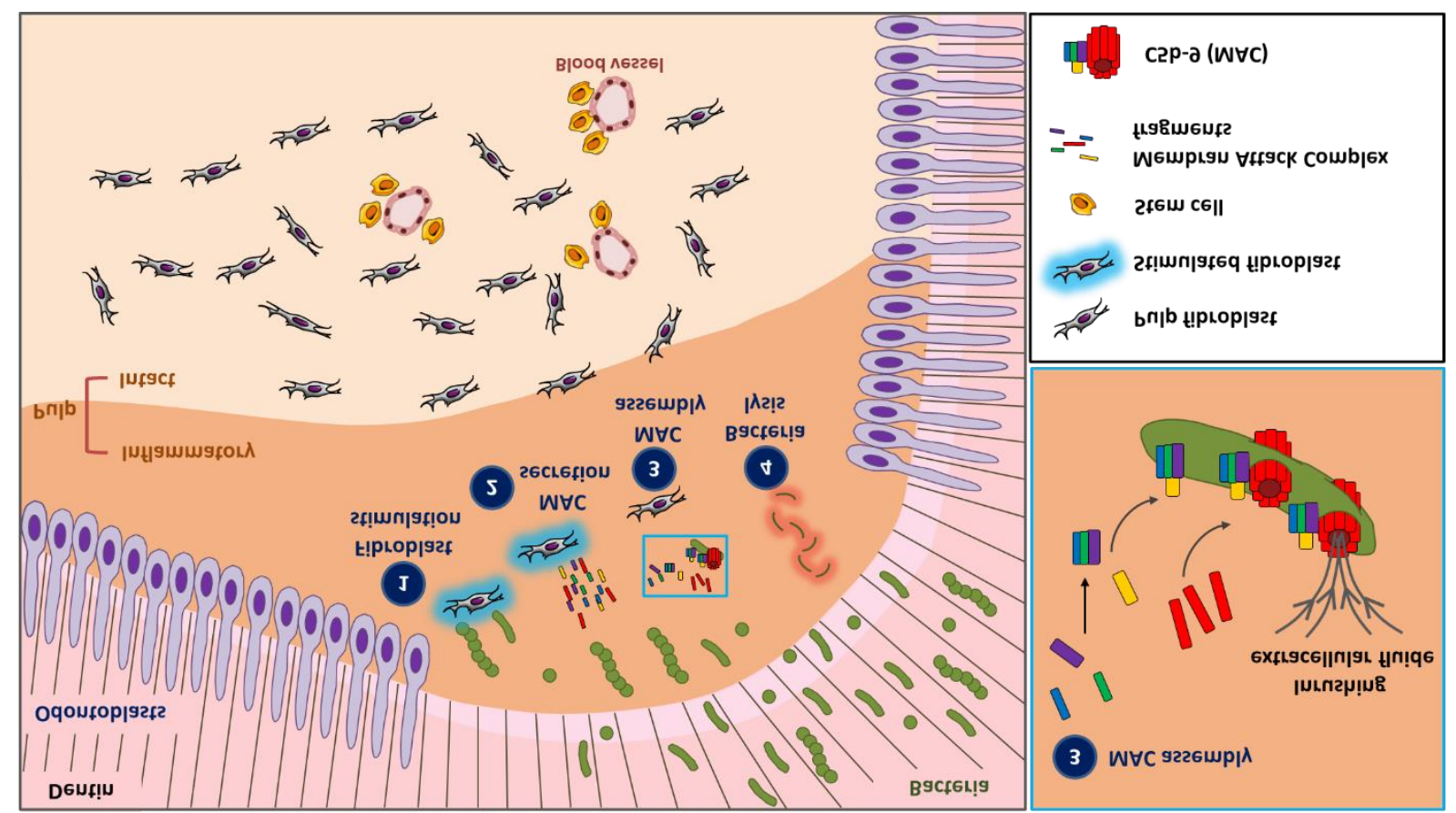

Figure 3: A sketch of Membrane Attack Complex (MAC) secretion by pulp fibroblasts and implication in cariogenic bacteria lysis

(1) Pulp fibroblast stimulation by cariogenic bacteria in the inflammatory area beneath the carious injury, (2) Stimulated fibroblasts secrete MAC components (C5b, C6, C7, C8 and C9). (3) These molecules assemble and polymerize to form lytic MAC on the surface of pathogens infiltrating the pulp. This step with a blue rectangle insert is amplified on the right showing MAC components assembly and polymerization on the pathogen membrane. (4) MAC polymerization forms transmembrane pores in the pathogen membranes leading to bacteria lysis [45]. 


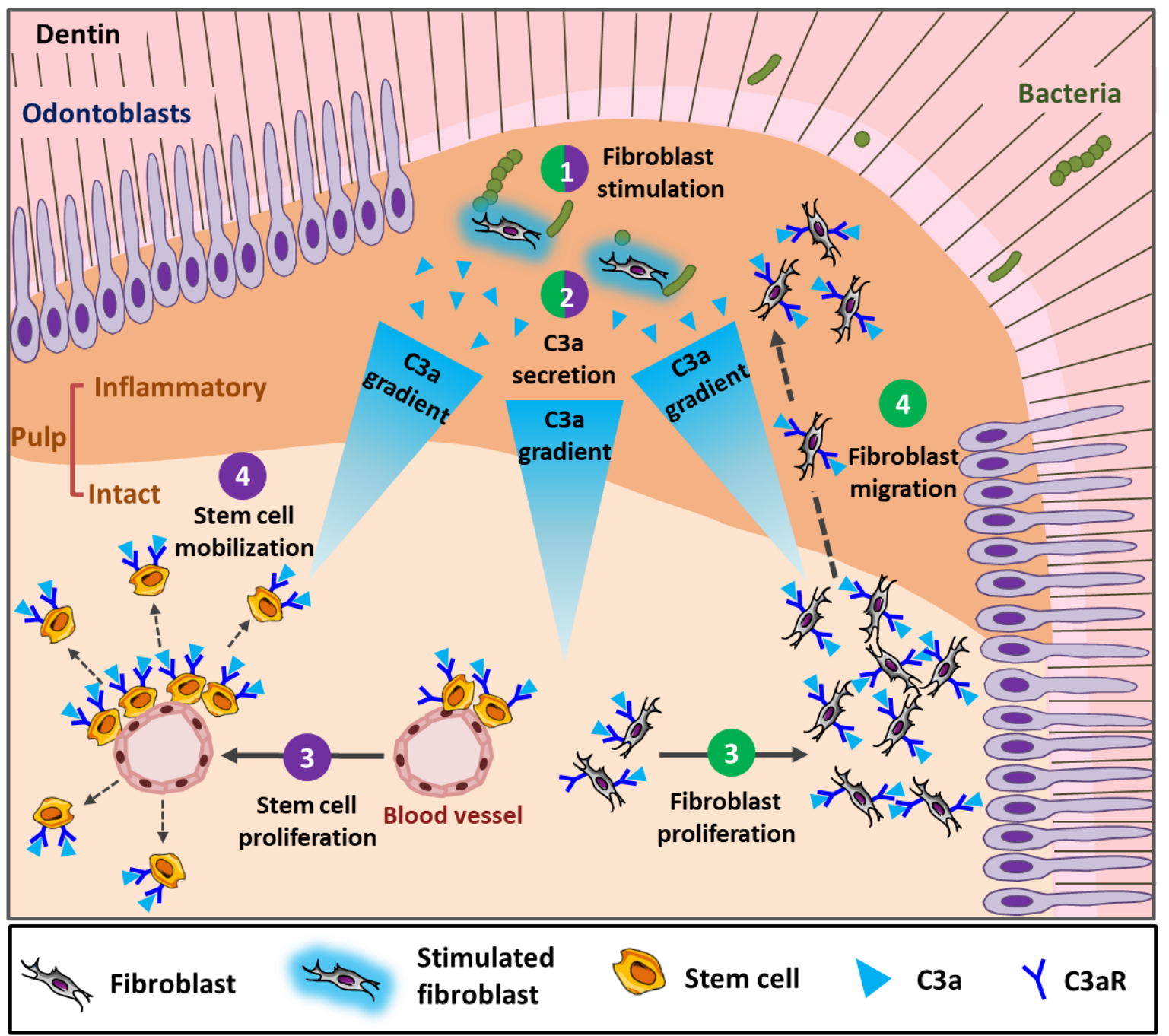

Figure 4: A sketch depicting fibroblast-released C3a under carious simulation and its implication in pulp cell proliferation, mobilization and recruitment.

(1) Pulp fibroblast stimulation by cariogenic bacteria in the inflammatory area beneath the carious injury, (2) fibroblasts secrete $\mathrm{C} 3 \mathrm{a}$. (3) This molecule interacts with its $\mathrm{C} 3 \mathrm{aR}$ receptors on pulp fibroblasts and DPSCs in the intact pulp area inducing pulp fibroblast and DPSC proliferation. (4) The resulting C3 gradient mobilizes stem cells and induces fibroblasts recruitment from the intact area to the stimulation site in the inflammatory area [46]. 


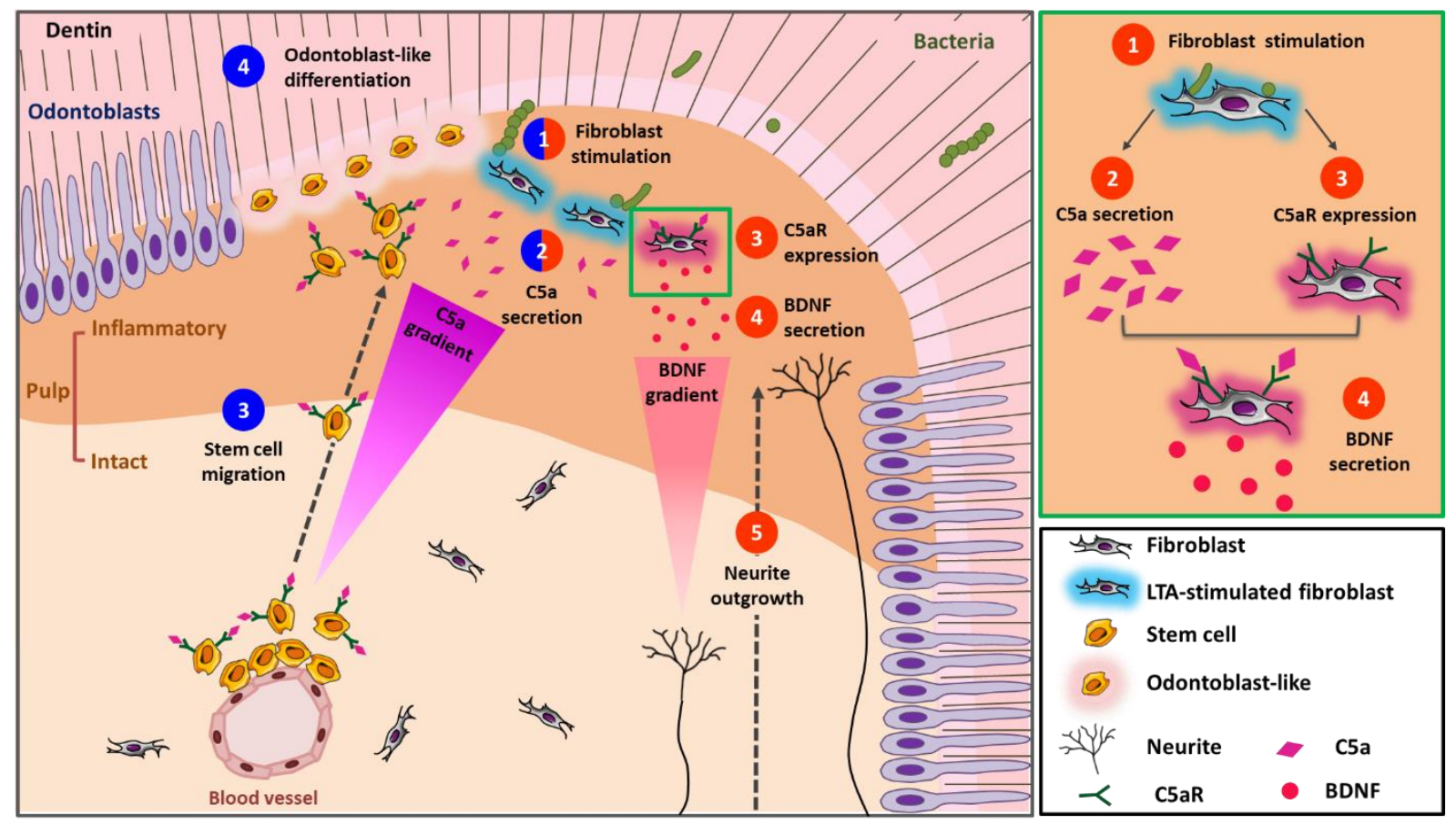

Figure 5: A sketch depicting fibroblast-released C5a effects under carious simulation and its implication in neurite growth and pulp stem cell recruitment and differentiation.

(1) Pulp fibroblast stimulation by cariogenic bacteria in the inflammatory area beneath the carious injury, (2) pulp fibroblasts secrete C5a [43]. (3) Interaction of C5a with C5aR expressed by DPSCs in the intact area leads to DPSC migration to the stimulation site [47], and (4) their subsequent differentiation into odontoblast-like cells [53]. On the other hand, (3) C5a fixation on fibroblast C5aR leads to (4) BDNF secretion from the inflammatory area towards the intact pulp, inducing (5) neurite outgrowth towards inflammatory area [49]. The green rectangle insert shows steps 1-4 from fibroblast stimulation to BDNF secretion. 


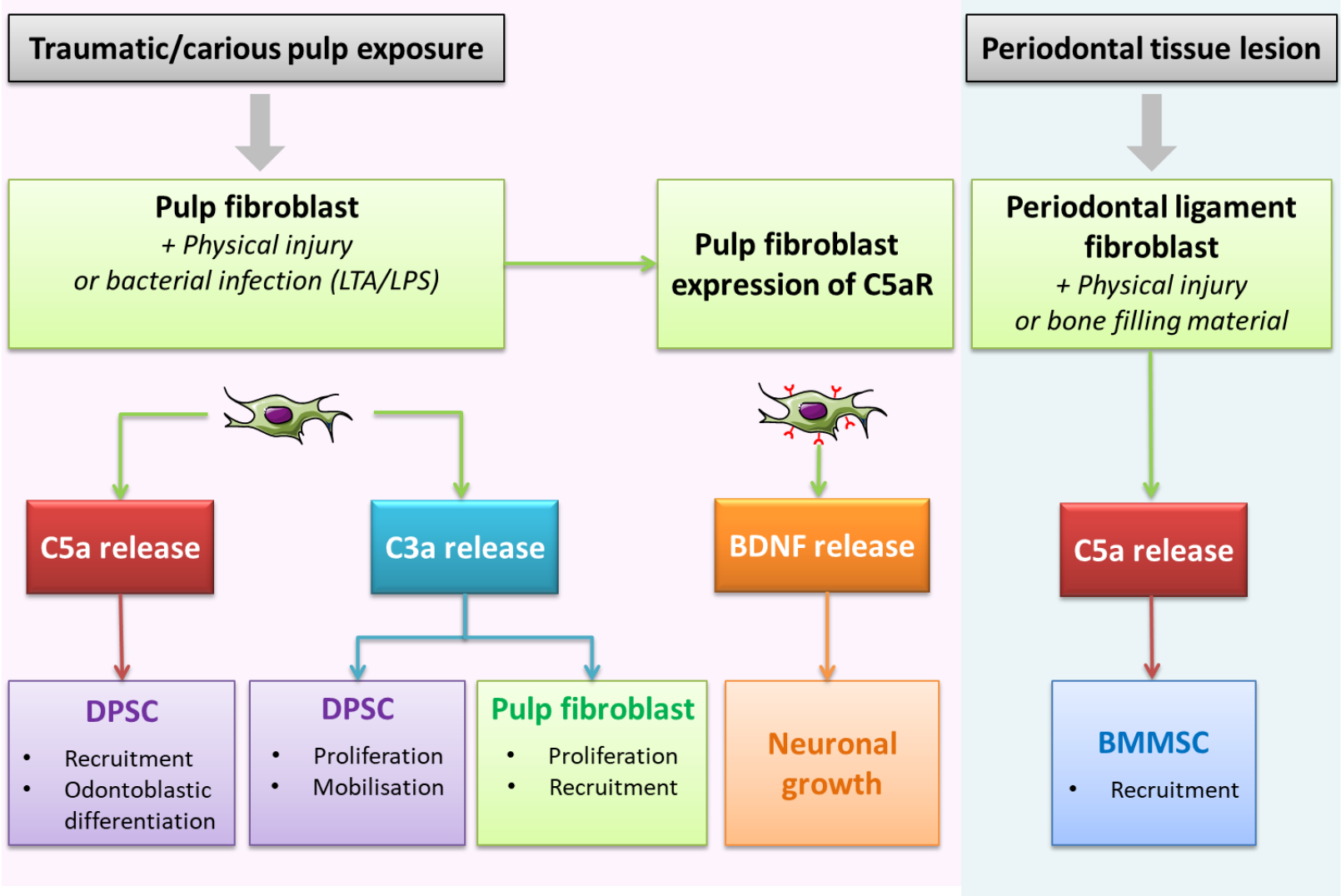

Figure 6: A sketch of local complement system activation and its effects on the initial steps of dental tissue regeneration.

Periodontal ligament cells and pulp fibroblasts produce Complement active molecules upon traumatic injury or infection. C3a released by injured or infected pulp fibroblasts induces pulp fibroblasts/pulp stem cells proliferation, mobilizes pulp stem cells and recruits pulp fibroblasts. Fibroblast-secreted C5a is involved in pulp stem cell recruitment/differentiation and neurite outgrowth through BDNF release. C5a released by Periodontal ligament cells recruits Bone Marrow Mesenchymal Stem Cell.

DPSC $=$ dental pulp stem cell

$\mathrm{BDNF}=$ Brain Derived Neurotrophic Factor

BMMSC=Bone Marrow Mesenchymal Stem Cell 


\section{Compliance with Ethical Standards}

Conflict of Interest: Madison Bergmann declares that he has no conflict of interest. Charlotte Jeanneau declares that he has no conflict of interest. Thomas Giraud declares that he has no conflict of interest. Gilles Richard declares that he has no conflict of interest. Imad About declares that he has no conflict of interest.

Funding: This work was supported by Aix-Marseille University and CNRS. Ethical approval: This article does not contain any studies with human participants or animals performed by any of the authors.

Informed consent: Informed consent was obtained from all individual participants included in the study. 


\section{Bibliography}

1. Fullerton JN, Gilroy DW (2016) Resolution of inflammation: a new therapeutic frontier. Nat Rev Drug Discov 15:551-567. https://doi.org/10.1038/nrd.2016.39

2. Pajarinen J, Lin T, Gibon E, et al (2019) Mesenchymal stem cell-macrophage crosstalk and bone healing. Biomaterials 196:80-89. https://doi.org/10.1016/j.biomaterials.2017.12.025

3. Feehan KT, Gilroy DW (2019) Is Resolution the End of Inflammation? Trends Mol Med 25:198214. https://doi.org/10.1016/j.molmed.2019.01.006

4. Schett G, Neurath MF (2018) Resolution of chronic inflammatory disease: universal and tissuespecific concepts. Nature Communications 9:3261. https://doi.org/10.1038/s41467-018-058006

5. Maruyama M, Rhee C, Utsunomiya T, et al (2020) Modulation of the Inflammatory Response and Bone Healing. Front Endocrinol 11:. https://doi.org/10.3389/fendo.2020.00386

6. Godwin JW, Pinto AR, Rosenthal NA (2013) Macrophages are required for adult salamander limb regeneration. PNAS 110:9415-9420. https://doi.org/10.1073/pnas.1300290110

7. Winkelstein JA, Sullivan KE (2010) CHAPTER 11 - Complement Deficiencies. In: Leung DYM, Sampson HA, Geha R, Szefler SJ (eds) Pediatric Allergy: Principles and Practice (Second Edition). W.B. Saunders, Edinburgh, pp 119-132

8. Ehrnthaller C, Huber-Lang M, Nilsson P, et al (2013) Complement C3 and C5 deficiency affects fracture healing. PLoS ONE 8:e81341. https://doi.org/10.1371/journal.pone.0081341

9. Rutkowski MJ, Sughrue ME, Kane AJ, et al (2010) The complement cascade as a mediator of tissue growth and regeneration. Inflamm Res 59:897-905. https://doi.org/10.1007/s00011-010-02206

10. Nesargikar PN, Spiller B, Chavez R (2012) The complement system: history, pathways, cascade and inhibitors. Eur $J$ Microbiol Immunol (Bp) 2:103-111. https://doi.org/10.1556/EuJMI.2.2012.2.2

11. Thorgersen EB, Barratt-Due A, Haugaa H, et al (2019) The Role of Complement in Liver Injury, Regeneration, and Transplantation. Hepatology 70:725-736. https://doi.org/10.1002/hep.30508

12. Lubbers R, Essen MF van, Kooten C van, Trouw LA (2017) Production of complement components by cells of the immune system. Clinical \& Experimental Immunology 188:183-194. https://doi.org/10.1111/cei.12952

13. Merle NS, Church SE, Fremeaux-Bacchi V, Roumenina LT (2015) Complement System Part I Molecular Mechanisms of Activation and Regulation. Front Immunol 6:. https://doi.org/10.3389/fimmu.2015.00262

14. Diebolder CA, Beurskens FJ, de Jong RN, et al (2014) Complement is activated by IgG hexamers assembled at the cell surface. Science 343:1260-1263. https://doi.org/10.1126/science.1248943 
15. Mortensen SA, Sander B, Jensen RK, et al (2017) Structure and activation of C1, the complex initiating the classical pathway of the complement cascade. Proc Natl Acad Sci USA 114:986-991. https://doi.org/10.1073/pnas.1616998114

16. Endo $Y$, Matsushita M, Fujita $T$ (2011) The role of ficolins in the lectin pathway of innate immunity. Int J Biochem Cell Biol 43:705-712. https://doi.org/10.1016/j.biocel.2011.02.003

17. Mödinger Y, Teixeira GQ, Neidlinger-Wilke C, Ignatius A (2018) Role of the Complement System in the Response to Orthopedic Biomaterials. Int J Mol Sci 19:. https://doi.org/10.3390/ijms19113367

18. Hawksworth OA, Li XX, Coulthard LG, et al (2017) New concepts on the therapeutic control of complement anaphylatoxin receptors. Molecular Immunology 89:36-43. https://doi.org/10.1016/j.molimm.2017.05.015

19. Merle NS, Noe R, Halbwachs-Mecarelli L, et al (2015) Complement System Part II: Role in Immunity. Front Immunol 6:. https://doi.org/10.3389/fimmu.2015.00257

20. Haas P-J, van Strijp J (2007) Anaphylatoxins: their role in bacterial infection and inflammation. Immunol Res 37:161-175. https://doi.org/10.1007/bf02697367

21. Coulthard LG, Woodruff TM (2015) Is the complement activation product C3a a proinflammatory molecule? Re-evaluating the evidence and the myth. J Immunol 194:3542-3548. https://doi.org/10.4049/jimmunol.1403068

22. Dunkelberger JR, Song W-C (2010) Complement and its role in innate and adaptive immune responses. Cell Res 20:34-50. https://doi.org/10.1038/cr.2009.139

23. van Lookeren Campagne $M$, Verschoor A (2018) Pathogen clearance and immune adherence "revisited": Immuno-regulatory roles for CRIg. Seminars in Immunology 37:4-11. https://doi.org/10.1016/j.smim.2018.02.007

24. Bayly-Jones C, Bubeck D, Dunstone MA (2017) The mystery behind membrane insertion: a review of the complement membrane attack complex. Philos Trans R Soc Lond, B, Biol Sci 372:. https://doi.org/10.1098/rstb.2016.0221

25. Del Rio-Tsonis K, Tsonis PA, Zarkadis IK, et al (1998) Expression of the third component of complement, C3, in regenerating limb blastema cells of urodeles. J Immunol 161:6819-6824

26. Kimura $\mathrm{Y}$, Madhavan M, Call MK, et al (2003) Expression of complement 3 and complement 5 in newt limb and lens regeneration. J Immunol 170:2331-2339. https://doi.org/10.4049/jimmunol.170.5.2331

27. Mastellos D, Papadimitriou JC, Franchini S, et al (2001) A novel role of complement: mice deficient in the fifth component of complement (C5) exhibit impaired liver regeneration. J Immunol 166:2479-2486. https://doi.org/10.4049/jimmunol.166.4.2479

28. Mödinger Y, Löffler B, Huber-Lang M, Ignatius A (2018) Complement involvement in bone homeostasis and bone disorders. Seminars in Immunology 37:53-65. https://doi.org/10.1016/j.smim.2018.01.001

29. Sakiyama H, Nakagawa K, Kuriiwa K, et al (1997) Complement Cls, a classical enzyme with novel functions at the endochondral ossification center: immunohistochemical staining of activated $\mathrm{Cls}$ 
with a neoantigen-specific antibody. Cell Tissue Res 288:557-565. https://doi.org/10.1007/s004410050841

30. Troeberg L, Nagase $H$ (2012) Proteases involved in cartilage matrix degradation in osteoarthritis. Biochim Biophys Acta 1824:133-145. https://doi.org/10.1016/j.bbapap.2011.06.020

31. Ignatius A, Schoengraf P, Kreja L, et al (2011) Complement C3a and C5a modulate osteoclast formation and inflammatory response of osteoblasts in synergism with IL-1 $\beta$. J Cell Biochem 112:2594-2605. https://doi.org/10.1002/jcb.23186

32. Ignatius A, Ehrnthaller C, Brenner RE, et al (2011) The anaphylatoxin receptor C5aR is present during fracture healing in rats and mediates osteoblast migration in vitro. J Trauma 71:952-960. https://doi.org/10.1097/TA.0b013e3181f8aa2d

33. Sinno H, Prakash S (2013) Complements and the Wound Healing Cascade: An Updated Review. Plast Surg Int 2013:. https://doi.org/10.1155/2013/146764

34. Rafail S, Kourtzelis I, Foukas PG, et al (2015) Complement Deficiency Promotes Cutaneous Wound Healing in Mice. The Journal of Immunology 194:1285-1291. https://doi.org/10.4049/jimmunol.1402354

35. Sinno H, Malhotra M, Lutfy J, et al (2012) Accelerated wound healing with topical application of $\begin{array}{lllll}\text { complement } \quad \text { C5. Plast } & \text { Reconstr } & \text { 130:523-529. }\end{array}$ https://doi.org/10.1097/PRS.0b013e31825dc02d

36. Sinno H, Malholtra M, Lutfy J, et al (2013) Topical application of complement C3 in collagen formulation increases early wound healing. J Dermatolog Treat 24:141-147. https://doi.org/10.3109/09546634.2011.631977

37. Sinno $\mathrm{H}$, Malhotra $\mathrm{M}$, Lutfy J, et al (2013) Complements $\mathrm{c} 3$ and $\mathrm{c} 5$ individually and in combination increase early wound strength in a rat model of experimental wound healing. Plast Surg Int 2013:243853. https://doi.org/10.1155/2013/243853

38. Abe $T$, Hosur KB, Hajishengallis $E$, et al (2012) Local complement-targeted intervention in periodontitis: proof-of-concept using a C5a receptor (CD88) antagonist. J Immunol 189:54425448. https://doi.org/10.4049/jimmunol.1202339

39. Hajishengallis $G$, Maekawa $T$, Abe $T$, et al (2015) Complement involvement in periodontitis: molecular mechanisms and rational therapeutic approaches. Adv Exp Med Biol 865:57-74. https://doi.org/10.1007/978-3-319-18603-0_4

40. Challacombe SJ, Shirlaw PJ, Thornhill MH (2015) Chapter 102 - Immunology of Diseases of the Oral Cavity. In: Mestecky J, Strober W, Russell MW, et al (eds) Mucosal Immunology (Fourth Edition). Academic Press, Boston, pp 1943-1983

41. Jeanneau C, Le Fournis C, About I (2019) Xenogeneic bone filling materials modulate mesenchymal stem cell recruitment: role of the Complement C5a. Clin Oral Investig. https://doi.org/10.1007/s00784-019-03087-5

42. Park SH, Ye L, Love RM, et al (2015) Inflammation of the Dental Pulp. Mediators Inflamm 2015:980196. https://doi.org/10.1155/2015/980196 
43. Chmilewsky F, Jeanneau C, Laurent P, About I (2014) Pulp fibroblasts synthesize functional complement proteins involved in initiating dentin-pulp regeneration. Am J Pathol 184:19912000. https://doi.org/10.1016/j.ajpath.2014.04.003

44. Le Fournis C, Hadjichristou C, Jeanneau C, About I (2019) Human Pulp Fibroblast Implication in Phagocytosis via Complement Activation. J Endod 45:584-590. https://doi.org/10.1016/j.joen.2018.10.023

45. Jeanneau C, Rufas P, Rombouts C, et al (2015) Can Pulp Fibroblasts Kill Cariogenic Bacteria? Role of Complement Activation. J Dent Res 94:1765-1772. https://doi.org/10.1177/0022034515611074

46. Rufas P, Jeanneau C, Rombouts C, et al (2016) Complement C3a Mobilizes Dental Pulp Stem Cells and Specifically Guides Pulp Fibroblast Recruitment. J Endod 42:1377-1384. https://doi.org/10.1016/j.joen.2016.06.011

47. Chmilewsky F, Jeanneau C, Laurent $P$, et al (2013) Pulp progenitor cell recruitment is selectively guided by a C5a gradient. J Dent Res 92:532-539. https://doi.org/10.1177/0022034513487377

48. Giraud T, Rufas P, Chmilewsky F, et al (2017) Complement Activation by Pulp Capping Materials Plays a Significant Role in Both Inflammatory and Pulp Stem Cells' Recruitment. J Endod 43:11041110. https://doi.org/10.1016/j.joen.2017.02.016

49. Chmilewsky F, About I, Chung S-H (2016) Pulp Fibroblasts Control Nerve Regeneration through Complement Activation. J Dent Res 95:913-922. https://doi.org/10.1177/0022034516643065

50. Liu M, Mu H, Peng W, et al (2019) Time-dependent C5a and C5aR expression in dental pulp cells following stimulation with LTA and LPS. Int J Mol Med 44:823-834. https://doi.org/10.3892/ijmm.2019.4246

51. Ohno $M$, Hirata $T$, Enomoto $M$, et al (2000) A putative chemoattractant receptor, $C 5 L 2$, is expressed in granulocyte and immature dendritic cells, but not in mature dendritic cells. Mol Immunol 37:407-412. https://doi.org/10.1016/s0161-5890(00)00067-5

52. Li R, Coulthard LG, Wu MCL, et al (2013) C5L2: a controversial receptor of complement anaphylatoxin, C5a. FASEB J 27:855-864. https://doi.org/10.1096/fj.12-220509

53. Chmilewsky F, Liang R, Kanazawa M, et al (2019) C5L2 Regulates DMP1 Expression during Odontoblastic Differentiation. J Dent Res 98:597-604. https://doi.org/10.1177/0022034518820461

54. Chmilewsky F, About I, Chung SH (2017) C5L2 Receptor Represses Brain-Derived Neurotrophic Factor Secretion in Lipoteichoic Acid-Stimulated Pulp Fibroblasts. J Dent Res 96:92-99. https://doi.org/10.1177/0022034516673832

55. Chmilewsky F, About I, Cooper LF, Chung SH (2018) C5L2 Silencing in Human Pulp Fibroblasts Enhances Nerve Outgrowth Under Lipoteichoic Acid Stimulation. Journal of Endodontics 44:1396-1401. https://doi.org/10.1016/j.joen.2018.05.004

56. Natarajan N, Abbas Y, Bryant DM, et al (2018) Complement Receptor C5aR1 Plays an Evolutionarily Conserved Role in Successful Cardiac Regeneration. Circulation 137:2152-2165. https://doi.org/10.1161/CIRCULATIONAHA.117.030801 
57. Matsumoto N, Satyam A, Geha M, et al (2017) C3a Enhances the Formation of Intestinal Organoids through C3aR1. Front Immunol 8:1046. https://doi.org/10.3389/fimmu.2017.01046

58. Matsuoka K, Park K-A, Ito M, et al (2014) Osteoclast-derived complement component 3a stimulates osteoblast differentiation. J Bone Miner Res 29:1522-1530. https://doi.org/10.1002/jbmr.2187

59. Peterson SL, Nguyen HX, Mendez OA, Anderson AJ (2015) Complement protein C1q modulates neurite outgrowth in vitro and spinal cord axon regeneration in vivo. J Neurosci 35:4332-4349. https://doi.org/10.1523/JNEUROSCl.4473-12.2015

60. Fayyazi A, Sandau R, Duong LQ, et al (1999) C5a Receptor and Interleukin-6 Are Expressed in Tissue Macrophages and Stimulated Keratinocytes but not in Pulmonary and Intestinal Epithelial Cells. The American Journal of Pathology 154:495-501. https://doi.org/10.1016/S00029440(10)65295-9

61. Katz Y, Nadiv O, Rapoport MJ, Loos M (2000) IL-17 regulates gene expression and protein synthesis of the complement system, C3 and factor B, in skin fibroblasts. Clinical \& Experimental Immunology 120:22-29. https://doi.org/10.1046/j.1365-2249.2000.01199.x 